\title{
The Association Between Time Spent Using Entertainment Media and Marital Quality in a Contemporary Dyadic National Sample
}

Jeffrey P. Dew

Brigham Young University - Provo, jeff_dew@byu.edu

Sarah Tulane

Utah State University

Follow this and additional works at: https://scholarsarchive.byu.edu/facpub

Part of the Other Social and Behavioral Sciences Commons

\section{Original Publication Citation}

Dew, J. P., \& Tulane, S.* (2015). The association between time spent using entertainment media and marital quality in a contemporary national sample. Journal of Family and Economic Issues, $36,621-632$.

\section{BYU ScholarsArchive Citation}

Dew, Jeffrey P. and Tulane, Sarah, "The Association Between Time Spent Using Entertainment Media and Marital Quality in a Contemporary Dyadic National Sample" (2015). Faculty Publications. 4533.

https://scholarsarchive.byu.edu/facpub/4533 


\title{
The Association Between Time Spent Using Entertainment Media and Marital Quality in a Contemporary Dyadic National Sample
}

\author{
Jeffrey Dew $\cdot$ Sarah Tulane
}

Published online: 30 June 2015

(c) Springer Science+Business Media New York 2015

\begin{abstract}
This study used the Actor Partner Interdependence Model and a national sample of married couples ( $N=1368)$ to explore the relationship between entertainment media use and marital satisfaction, conflict, and perceived marital instability. Entertainment media-use included newer types of media (e.g., social networking websites) as well as traditional media (e.g., television). A number of negative relationships between media use and wives' and husbands' marital quality emerged. Husbands' use of social networking websites, in particular, was associated with many of the marital quality variables. The effect sizes of media use were small, however. We also explored whether the relationship worked in reverse and whether media use differences between the spouses would relate to marital quality. When spouses reported different levels of using video games, they also reported lower levels of marital quality. The findings suggest that as media technology continues to change, it may relate to marital quality in new ways.
\end{abstract}

Keywords Marriage - Media - Time use - Technology · Television $\cdot$ Social networking websites $\cdot$ Video games

J. Dew $(\bowtie)$

Family, Consumer, and Human Development, Utah State University, Logan, UT 84321, USA

e-mail: jeff.dew@usu.edu

S. Tulane

Family, Consumer, and Human Development, Utah State University, Family Life Building 116B 2905 Old Main Hill, Logan, UT 84322-2905, USA

e-mail: sarah.tulane@usu.edu

\section{Introduction}

Technology has changed the landscape of family interactions. For example, using technology, family members can be more accessible to each other throughout the day. Further, entertainment media has become more interactive, often forcing family members to choose between interacting with each other or with the media. And although individuals utilize entertainment media almost daily (Chesley 2005), few studies have examined how new interactive entertainment media such as social networking sites and gaming (i.e., playing video games) is associated with marital quality. This is unfortunate given that the need exists to understand how technology functions in the context of family relationships (Hughes and Hans 2001). Daly (2003) proposed that in daily family living, there are things that take up time, energy, and attention, but are not included in family theory. Given that media consumption accounted for more than $10 \%$ of individuals' daily time use, on average in a recent study (Bureau of Labor Statistics 2010), understanding the association between media use and marital quality would give researchers insight into contemporary families.

This exploratory study addressed the gap in the literature by examining the association between entertainment media use and marital quality. It adds to the literature in a number of ways. First, it examined this question using national data (though see also Coyne et al. 2011). Second, participants responded to the survey in late 2010 and early 2011 making the data contemporary. Third, the data contained responses from both spouses in each marriage. This allowed us to examine how each participant's reported media use is associated with their own measures of marital quality, and also with their spouse's marital quality using the Actor Partner Interdependence Model (APIM, Kashy and Kenny 
2000). Having both spouses' responses also allowed us to test whether differences in spouses' media use were associated with marital quality. Fourth, we examined both directions of this association (i.e., with the direction of the association reversed). Fifth, in addition to questioning participants about standard entertainment media (e.g., television), the survey also asked about more interactive technologies such as social networking sites and gaming. Researchers have suggested that newer media, such as gaming, is lacking in the literature regarding romantic relationships (Hertlein and Hawkins 2012). Finally, we used multiple dimensions of marital quality-marital satisfaction, marital conflict, and perceived marital instability.

\section{Media Use and Marital Quality}

\section{An Exploratory Study}

Media use can have both positive and negative aspects. For example, on the one hand individuals watch television to relax as well as for excitement (Bryant and Zillmann 1984), others play video or computer games to recover from stress and relax (Reinecke 2009), and many use social networking to share positive thoughts and foster relationships (Walker et al. 2009). On the other hand, some watch television to avoid dealing with problems (Henning and Vorderer 2001), online video gaming may replace offline social relationships (Sublette and Mullan 2010), and using social networking websites is sometimes associated with increased jealousy in romantic relationships (Muise et al. 2009).

Because few studies have examined the association between media use and marital quality (especially gaming and social networking website use), we have few theoretical guides with which to frame this study. Social exchange theory would argue that depending on whether media use is an overall relationship cost or benefit, it could either be negatively or positively associated with marital quality. But this does not give us a way of predicting one effect or the other. We are able, however, to examine how different types of media use are associated with marital quality in a sample that includes both the wives and the husbands of each couple.

An additional issue adding to theoretical complexity is that of directionality. Although most previous studies use the idea that media use is exogenous to relationship quality, this assumption does not always hold. For example, life dissatisfaction and emotional instability is associated with increases in social media use (Correa et al. 2009). It is highly likely that different levels of marital quality may be associated with decreased or increased media use. No theory of which we are aware accounts for the possibility of bidirectional effects.
For these reasons, this study is exploratory. We do make hypotheses when prior studies are sufficiently clear to do so. But sometimes phenomena are too new to be able to use an existing theory as a foundation for their study. Gaming and social networking websites are two such phenomena. Although we do not test a specific theory, we suggest that value still exists in exploring the association between media use and marital quality using a national sample that includes both spouses.

\section{Frequency of Media Use}

Our first area of exploration concerns the relationship between frequency of different types of media use and different measures of marital quality. A few previous studies have examined this relationship. The majority of these studies, however, have used convenience samples (Ahlstrom et al. 2012; Baym et al. 2007; Clayton et al. 2013; Muise et al. 2009) and few of them have examined gaming and the use of social networking websites (Ahlstrom et al. 2012; Clayton et al. 2013; Coyne et al. 2011; Hand et al. 2013; Hertlein and Hawkins 2012; Muise et al. 2009). These studies are split regarding the merits of media use vis-à-vis marital quality.

We used the Actor Partner Interdependence Model (APIM, Kashy and Kenny 2000) analytic framework to test our hypotheses. The APIM was explicitly created to analyze data from dyads and social groups. It recognizes both "actor effects" and "partner effects" (Kashy and Kenny 2000; Kenny et al. 2006). Actor effects are the ways in which participants' attitudes/behaviors/etcetera are associated with their own outcomes, whereas partner effects are the ways in which spousal attitudes/behaviors/etcetera are associated with participant outcomes. Our conceptual model of the association between media use and marital quality within the APIM is shown in Fig. 1. Figure 1 suggests that wives' and husbands' media use is associated with their own marital quality (i.e., the actor effects) and their spouses' marital quality (i.e., the partner effects).

Television. Some studies regarding television and marriage have found that it is positively associated with marital quality. Television watching is one form of leisure which couples have in common (Gantz 1985; Glorieux et al. 2011). Further, watching TV is an activity couples often do jointly more so than individually (Glorieux et al. 2011); shared leisure is positively associated with marital quality (Dew 2007; Hill 1998). Gantz (1985) found that shared television viewing was a valued activity for married people. However, it is important to note Osborn's (2012) finding that heavily viewing content with romantic themes was associated with negative outcomes for relationships, such as a lower commitment to the marriage. Given these findings, we hypothesize that the frequency of television 
Fig. 1 Conceptual actor partner interdependence model of the association between amount of entertainment media use, spousal time, and marital quality

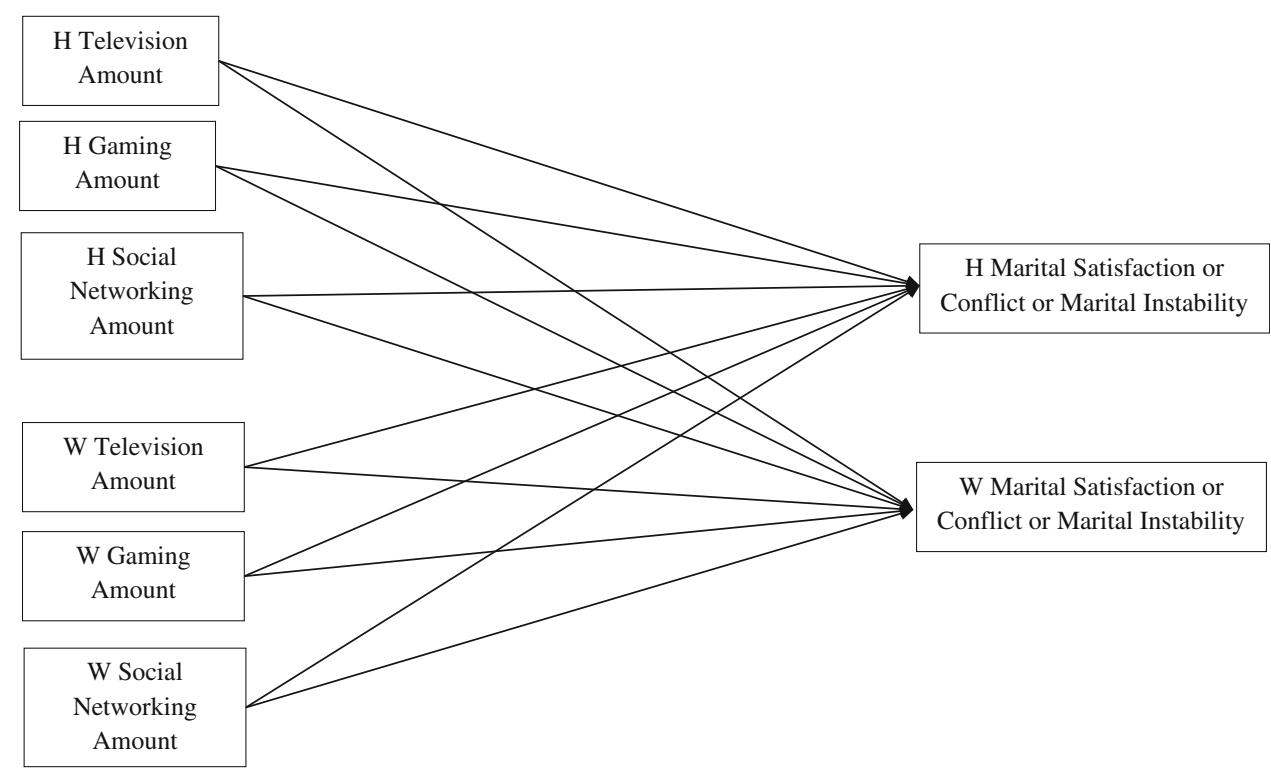

use will be positively associated with marital satisfaction and negatively associated with conflict and perceived marital instability.

Gaming. Like any media type, gaming could potentially be positively associated with relationship quality. For example, video and computer games are often used to recover from daily stresses and strains (Reinecke 2009). Ostensibly, then, using video games to recover from a stressful day might help an individual to have more positive interactions with their spouse later.

Research addressing gaming and romantic relationships is sparse (Hertlein and Hawkins 2012). Of the research available, both negative and positive findings exist. On the negative side, gaming is associated with lower relationship satisfaction because of lost time with one's spouse (e.g., "gaming widows" or "widowers") (Ahlstrom et al. 2012; Cole and Griffiths 2007; Padilla-Walker et al. 2009). Further, men's gaming is positively associated with increased conflict in romantic relationships (Coyne et al. 2012). On the positive side, however, gaming can have positive outcomes when spouses game together (Ahlstrom et al. 2012). Because previous studies have typically found a negative relationship, we hypothesize that participants' frequency of gaming will be negatively associated with marital satisfaction and positively associated with marital conflict and perceived marital instability. We also hypothesize that partner effects may be particularly salient. That is, a participants' report of their gaming may be negatively related to their spouses' reports of marital satisfaction and positively related to their spouses' reports of conflict and perceived marital instability.

Social networking websites. Like gaming, the studies that exist on social media have suggested that it might be negatively associated with relationship quality. Intimacy in romantic relationships and the perception of a romantic partner's use of social media is negatively associated (Hand et al. 2013). Further, increased Facebook (one of the largest social networking websites) use was related to an increase in jealousy in romantic relationships (Muise et al. 2009) and negative relationship outcomes, including divorce $^{1}$ (Clayton et al. 2013). Furthermore, research surrounding the initiation of online infidelity, pornography, and cybersex is increasing (Doran and Price 2014; Fincham and Beach 2010). Given these findings, we expect that frequency of social networking will be negatively associated with marital satisfaction and positively associated with conflict and perceived marital instability. Partner effects may also be especially salient.

\section{Marital Quality as Exogenous}

We are sensitive to the idea that media use might not be exogenous to marital quality. That is, marital quality might drive an individual's media use, rather than the other way around. In a low-quality marriage, spouses might engage in more media use to compensate for the poor relationship. These individuals may use media use as a way to cope with their relationship. For example, they might seek out intimacy and support in other relationships using social networking websites. Alternatively, individuals with hostile spouses might use television or gaming as a way to avoid their spouse. Researchers have found that dissatisfaction

\footnotetext{
${ }^{1}$ One ecological study of internet access and internet penetration has found that the presence of the internet itself is not associated with divorce increases (Kendall, 2011).
} 
with life and emotional instability is associated with increases in social media use (Correa et al. 2009), so the possibility of relationship quality predicting media use does exist. Because this is an exploratory study, and because we do not have longitudinal data, we test this possibility. We want to be thorough in our investigation of these associations.

\section{Gender Norms and Media Use}

Established gender differences in media consumption exist; these gendered norms often depend on the medium. For example, women are more likely to use social media to connect with others, and are more likely to use social media to hurt their partner compared to men (Coyne et al. 2011). Even though women are beginning to game more, it is still a male-dominated medium (Cole and Griffiths 2007). It is possible that the relationship between media use and marital quality follows violations of gender norms. That is, when women engage in more gaming and/or men engage in more social networking website use, participants will report lower marital satisfaction, higher marital conflict, and higher levels of perceived marital instability.

\section{Media Use Differences}

Thus far, all of our proposed associations suggest that the frequency of media use was the main issue. But media use may be most strongly related to marital quality if spouses' reports of media use frequency are not similar. That is, it may not be the frequency of different types of media use that is associated with marital quality. Rather, differences that exist between wives' and husbands' reports of their media use may be most strongly associated with marital quality.

A large difference in reports of media use may signify a number of different marital issues. Most simply, it could signify that one spouse is frequently spending a larger amount of time using media than the other spouse which would mean that the one spouse is frequently using media without the other spouse. Frequently engaging in media by oneself might make the other spouse upset that they are not engaged in joint leisure. Alternatively, such a division may signify that the relationship is already in trouble and that one spouse may be using media to avoid the other or to compensate for the relationship problems. Another possibility is that because this is self-report data, a large difference in media usage reports may simply indicate a difference in perceptions between wives and husband in the amount of media that they use. Unfortunately, we do not have the data to tease apart these alternatives. However, even though we cannot be certain of the mechanism, we hypothesize that larger differences between wives' and husbands' media use reports would be associated with lower marital satisfaction and higher levels of conflict and perceived marital instability.

\section{Method}

\section{Data/Sample}

This study used data drawn from the Survey of Marital Generosity (SMG). The SMG was designed to measure different dimensions of marriage with a particular focus on positive marital attitudes and behaviors as well as many multi-item measures of marital quality. We also included three measures of media use.

A survey research firm (Knowledge Networks) gathered the data for the SMG between December 2010 and February 2011. Individuals in the SMG were on a preexisting survey panel that Knowledge Networks created. This survey panel was generated using both random digit dialing and random address-based sampling utilizing national probability sampling techniques. The address based sampling used the US Postal Service's Delivery Sequence File and had the potential to reach $97 \%$ of US homes (Knowledge Networks 2011). Using address-based sampling allowed individuals to participate whether they had a land-line, a cell phone, or no phone at all. Individuals were either contacted by phone or by mail. Once they agreed to participate on the panel, Knowledge Networks provided them with equipment to connect to the internet so that they could take surveys electronically.

To create the SMG, participants already on the Knowledge Networks panel who were married and between the ages of 18 and 45 were invited to participate. Of the 4,510 individuals invited, 3,455 agreed to participate (1,745 wives and 1,705 husbands). This represents a $76.6 \%$ response rate. For participating, individuals were given points for which they could redeem consumer goods. The majority of the individuals (89\%) were married to each other, though $11 \%$ of the participants had a spouse who refused to take the survey. Because the data were collected electronically, we could not ensure that individuals completed the surveys independently, even though they were instructed to do so. For this study, we used all of the individuals' data whose spouse also participated $(N=1,368)$. Our use of the APIM precluded using those whose spouses did not participate.

\section{Measures}

We used two mean scales and one single item as our measures of marital quality. These included marital satisfaction, frequency of marital conflict, and perceived marital 
instability. Marital satisfaction was created by taking the mean of four items that asked how happy participants were about different dimensions of their relationships. The four dimensions were love, respect, communication, and sex. Response sets ranged from 1 (Very Unhappy) to 5 (Very Happy). Cronbach's alpha for the scale was .89 for wives and .89 for husbands.

We created the variable measuring the frequency of marital conflict by scaling three items that asked couples how often they fought about different topics. The topics included chores, money, and children. We used a mean scale to account for the fact that some participants did not have children at home and did not answer that question. The response set ranged from 1 (Never) to 6 (Almost Every Day). The Cronbach's alpha for this scale was .73 for wives and .75 for husbands. Finally, perceived marital instability was taken from an item that asked participants about the probability that their marriage would end in divorce. Participants could respond from 1 (Very Low) to 11 (Very High).

Three variables measured the frequency of media use. Each asked participants how much time they spent using a different types of media (i.e., television, gaming, and using social networking sites) on a typical weekday. The response set for each of these variables ranged from 1 (Not at $A l l$ ) to 7 (4 Hours or More). Unfortunately, we asked participants about their overall use of each type and not whether they were engaging in these activities alone or with their spouse. Thus, we were not able to separately evaluate personal media use and couple media use.

In addition to these variables, we created three difference score variables. We subtracted husbands' television use from wives' television use, husbands' social networking from wives' social networking, and husbands' gaming from wives' gaming. Consequently, a positive number for these variables indicated that wives engaged in the media activity more frequently, whereas a negative number indicated that husbands engaged in the media activity more frequently. A difference score of zero indicated that husbands and wives engaged in the media activity at the same levels. After creating these difference scores, we mean centered them and squared them to check for curvilinear relationships.

We also included control covariates to help account for third variable problems. The variables that we used as control covariates were participants' age, education (measured on a scale from 1 to 14), and total household income (measured on a scale from 1 to 19). These variables were included in each of the structural equation models. All of the exogenous variables were grand mean-centered (Kenny et al. 2006).

Table 1 shows the descriptive statistics for the participants. On average, wives and husbands reported high levels of marital satisfaction (mean of 3.85 out of 5), low to moderate levels of marital conflict, and low levels of
Table 1 Descriptive Statistics

\begin{tabular}{|c|c|c|c|c|c|c|}
\hline & \multicolumn{3}{|l|}{ Wives } & \multicolumn{3}{|c|}{ Husbands } \\
\hline & $\begin{array}{l}M \text { or } \\
\%\end{array}$ & $\mathrm{StD}$ & Range & $\begin{array}{l}M \text { or } \\
\%\end{array}$ & $\mathrm{StD}$ & Range \\
\hline Marital satisfaction & 3.85 & .88 & $1-5$ & 3.84 & .86 & $1-5$ \\
\hline Marital conflict & 2.26 & .88 & $1-6$ & 2.22 & .84 & $1-6$ \\
\hline $\begin{array}{l}\text { Perceived marital } \\
\text { instability }\end{array}$ & 2.27 & 2.06 & $1-11$ & 2.26 & 2.01 & $1-11$ \\
\hline $\begin{array}{l}\text { Time spent watching } \\
\text { television }\end{array}$ & 4.59 & 1.72 & $1-7$ & 4.57 & 1.69 & $1-7$ \\
\hline $\begin{array}{l}\text { Time spent using } \\
\text { social networking } \\
\text { websites }\end{array}$ & 2.82 & 1.67 & $1-7$ & 2.18 & 1.43 & $1-7$ \\
\hline Time spent gaming & 1.87 & 1.40 & $1-7$ & 2.30 & 1.66 & $1-7$ \\
\hline Age & 35.28 & 5.74 & $18-45$ & 36.71 & 5.62 & $19-45$ \\
\hline Education & 11.15 & 1.58 & $3-14$ & 11.06 & 1.67 & $1-14$ \\
\hline $\begin{array}{l}\text { Total household } \\
\text { income }\end{array}$ & 13.05 & 3.43 & $1-19$ & 13.05 & 3.43 & $1-19$ \\
\hline Black & 3.2 & & & 5.0 & & \\
\hline Hispanic & 8.8 & & & 8.4 & & \\
\hline Other & 8.3 & & & 7.2 & & \\
\hline
\end{tabular}

perceived marital instability. Of the media use types, husbands and wives watched television most frequently with a mean on the 7 point scale between 4.57 and 4.59. On the scale, a score of four corresponds to "over $1 \mathrm{~h}$ per day but under $2 \mathrm{~h}$," whereas a score of five corresponds to "over $2 \mathrm{~h}$ per day but under $3 \mathrm{~h}$." Wives spent more time on social networking websites than husbands, whereas husbands spent more time gaming than wives. Participants were in their mid-30 s, on average, had a mean education level that corresponded with some college, and had an average household income between $\$ 50,000$ and $\$ 60,000$. As also can be seen in Table 1, the data underrepresented Black couples. Among individuals who were between the ages of 18 and 45 and married in 2012, the General Social Survey (a nationally representative sample) had $71.5 \%$ White, $11 \%$ Black, and $17.5 \%$ of another race/ethnicity.

\section{Analysis}

We used path models to examine the association between media use and marital quality within the framework of the APIM. Path analysis allows us to simultaneously run many multiple regressions. It allows us to simultaneously test both the actor (participant exogenous to participant endogenous) pathways and the partner (spouse exogenous to participant endogenous) pathways (Fig. 1). For example in our first path model we used both husbands' marital satisfaction and wives' marital satisfaction as endogenous variables. Path modeling and SEM are frequently used to test APIM models (Kenny et al. 2006). 
Table 2 Participant-reported media use predicting marital satisfaction, conflict, and divorce proneness

\begin{tabular}{|c|c|c|c|c|c|c|c|c|c|c|c|c|}
\hline & \multicolumn{4}{|c|}{ Satisfaction } & \multicolumn{4}{|l|}{ Conflict } & \multicolumn{4}{|c|}{$\begin{array}{l}\text { Perceived marital } \\
\text { instability }\end{array}$} \\
\hline & \multicolumn{2}{|l|}{ Wives } & \multicolumn{2}{|c|}{ Husbands } & \multicolumn{2}{|l|}{ Wives } & \multicolumn{2}{|c|}{ Husbands } & \multicolumn{2}{|l|}{ Wives } & \multicolumn{2}{|c|}{ Husbands } \\
\hline & $\beta$ & $S E$ & $\beta$ & $S E$ & $\beta$ & $S E$ & $\beta$ & $S E$ & $\beta$ & $S E$ & $\beta$ & $S E$ \\
\hline Wives' time spent watching television & -.03 & .02 & -.04 & .02 & .03 & .02 & .05 & .02 & .02 & .04 & $.08 *$ & .04 \\
\hline Wives' time spent gaming & -.01 & .02 & -.01 & .02 & $.07 *$ & .02 & .04 & .02 & $.06^{*}$ & .04 & $.07 *$ & .04 \\
\hline Wives' time spent using social networking websites & .02 & .02 & .03 & .02 & -.06 & .02 & -.04 & .02 & -.01 & .04 & .02 & .04 \\
\hline Husbands' time spent watching television & $-.08^{*}$ & .02 & -.03 & .02 & .03 & .02 & .04 & .02 & .03 & .04 & .04 & .04 \\
\hline Husbands' time spent gaming & .02 & .02 & -.02 & .02 & -.02 & .02 & .01 & .02 & -.03 & .04 & .03 & .04 \\
\hline $\begin{array}{l}\text { Husbands' time spent using social networking } \\
\text { websites }\end{array}$ & $-.06^{*}$ & .02 & -.05 & .02 & $.12 * * *$ & .02 & $.06^{*}$ & .02 & $.08 * *$ & .04 & $.07 *$ & .04 \\
\hline Participant age & -.03 & .01 & $-.07 * *$ & .01 & -.03 & .01 & -.02 & .01 & .05 & .01 & $.06 *$ & .01 \\
\hline Participant Education & .04 & .01 & .01 & .01 & -.05 & .01 & -.04 & .01 & -.02 & .03 & -.03 & .03 \\
\hline Total household income & .01 & .01 & .03 & .01 & -.04 & .01 & -.05 & .01 & $-.06^{*}$ & .02 & -.04 & .02 \\
\hline $\mathrm{R}^{2}$ & .01 & & .01 & & .03 & & .02 & & .03 & & .03 & \\
\hline \multicolumn{13}{|l|}{ Path model fit statistics: } \\
\hline $\mathrm{X}^{2}$ & \multicolumn{4}{|c|}{$237.70 * * *$} & \multicolumn{4}{|l|}{$217.07 * * *$} & \multicolumn{4}{|c|}{$227.73 * * *$} \\
\hline CFI & \multicolumn{4}{|c|}{.96} & \multicolumn{4}{|l|}{.96} & \multicolumn{4}{|l|}{.96} \\
\hline RMSEA & \multicolumn{4}{|l|}{.09} & \multicolumn{4}{|l|}{.09} & \multicolumn{4}{|l|}{.09} \\
\hline
\end{tabular}

Satisfaction, conflict, and perceived marital instability were analyzed in separate path models. Wives and husbands variables were in the same models as per the APIM. Shaded cells indicate potential partner effects

$* p<.05$. ** $p<.01$. *** $p<.001$

We decided to run a separate path model for each marital quality variable (i.e., satisfaction, conflict, and perceived instability) rather than try to scale them together or create a latent variable. Although each of these variables relate to the idea of marital quality, they all measure a different aspect of quality. By running them in separate models, we were able to examine the unique relationship between the media use variables and each particular marital quality variable.

As with the marital quality variables, we did not create a latent variable from the media use variables. Rather, we treated them as observed variables. We observed that the interactive nature of social networking sites and gaming might make them qualitatively different than the more passive nature of television. Further, these variables were different enough from each other that they might not form a uniform scale. A Cronbach's alpha analysis justified this analytical decision as the Cronbach's alphas were low when we tried to scale them.

\section{Results}

Frequency of Media Use and Marital Quality

Table 2 shows the estimates ${ }^{2}$ of the APIM for the satisfaction, conflict, and perceived marital instability models.
Although the Chi Square for each model was significant, this was unsurprising given the large sample size (Yadama and Pandey 1995). Alternative fit measures suggested that models fit the data sufficiently $(\mathrm{CFI}=.96, \mathrm{RMSEA}=.09$ for each of the three models).

Turning first to marital satisfaction, the regression estimates evidenced only statistically significant partner effects for marital satisfaction. Husbands' television use $(\beta=-.08, p<.05)$ and using social networking websites $(\beta=-.06, \quad p<.05)$ were negatively associated with wives' marital satisfaction. Wives' media use was neither associated with their own nor their husbands marital satisfaction.

The results for marital conflict contained both actor and partner effects. Wives' time spent gaming $(\beta=.07$, $p<.05)$ was positively associated with their own reports of marital conflict while husbands' time spent using social networking websites $(\beta=.06, p<.05)$ was positively associated with their own reports of marital conflict. One partner effect emerged; husbands' reports of spending time using social networking websites were positively associated with wives' reports of marital conflict $(\beta=.12, p<.001)$.

The final columns in Table 2 show the results for perceived marital instability. Some of the findings were

\footnotetext{
2 The error estimates, and covariances are omitted in the interest of simplicity. .
} 
Table 3 Participant-reported marital quality predicting television, gaming, and social networking frequency

\begin{tabular}{|c|c|c|c|c|c|c|c|c|c|c|c|c|}
\hline & \multicolumn{4}{|l|}{ Television } & \multicolumn{4}{|l|}{ Gaming } & \multicolumn{4}{|c|}{ Social networking websites } \\
\hline & \multicolumn{2}{|l|}{ Wives } & \multicolumn{2}{|l|}{ Husbands } & \multicolumn{2}{|l|}{ Wives } & \multicolumn{2}{|l|}{ Husbands } & \multicolumn{2}{|l|}{ Wives } & \multicolumn{2}{|c|}{ Husbands } \\
\hline & $\beta$ & $S E$ & $\beta$ & $S E$ & $\beta$ & $S E$ & $\beta$ & $S E$ & $\beta$ & $S E$ & $\beta$ & $S E$ \\
\hline Wives' marital satisfaction & -.01 & .08 & -.05 & .07 & .05 & .06 & .03 & .07 & .02 & .07 & .02 & .06 \\
\hline Wives' marital conflict & -.01 & .07 & -.02 & .07 & .05 & .05 & -.01 & .06 & .01 & .07 & $.09 *$ & .06 \\
\hline Wives' perceived marital instability & .03 & .03 & .05 & .03 & .03 & .03 & -.04 & .03 & .02 & .03 & .04 & .03 \\
\hline Husbands' marital satisfaction & .02 & .07 & .03 & .07 & .04 & .06 & -.01 & .07 & .03 & .07 & .02 & .06 \\
\hline Husbands' marital conflict & .06 & .07 & .05 & .07 & .02 & .06 & .03 & .07 & -.01 & .07 & -.01 & .06 \\
\hline Husbands' perceived marital instability & .04 & .03 & .03 & .03 & $.10^{* *}$ & .03 & $.10^{* *}$ & .03 & $.09 *$ & .03 & $.08^{*}$ & .03 \\
\hline Participant age & .01 & .01 & $.08 * *$ & .01 & .01 & .01 & $-.14 * * *$ & .01 & $-.11 * * *$ & .01 & -.03 & .01 \\
\hline Participant education & $-.15^{* * *}$ & .03 & $-.16 * * *$ & .03 & $-.14 * * *$ & .03 & $-.10 * * *$ & .03 & $-.10 * * *$ & .03 & .02 & .02 \\
\hline Total household income & .02 & .02 & -.02 & .02 & $-.09 * *$ & .01 & $-.10 * * *$ & .01 & $-.06^{*}$ & .01 & $-.10 * * *$ & .01 \\
\hline $\mathrm{R}^{2}$ & .03 & & .04 & & .05 & & .07 & & .04 & & .03 & \\
\hline \multicolumn{13}{|l|}{ Path model fit statistics: } \\
\hline $\mathrm{X}^{2}$ & \multicolumn{4}{|l|}{$125.41 * * *$} & \multicolumn{4}{|l|}{$131.03 * * *$} & \multicolumn{4}{|l|}{$136.51 * * *$} \\
\hline CFI & \multicolumn{4}{|l|}{.98} & \multicolumn{4}{|l|}{.98} & \multicolumn{4}{|l|}{.98} \\
\hline RMSEA & \multicolumn{4}{|l|}{.06} & \multicolumn{4}{|l|}{.06} & \multicolumn{4}{|l|}{.07} \\
\hline
\end{tabular}

Television, gaming, and Social networking websites were analyzed in separate path models. Wives and husbands variables were in the same models as per the APIM. Shaded cells indicate potential partner effects

$* p<.05 . * * p<.01 . * * * p<.001$

similar to the conflict models. For example, wives' reports of gaming were positively associated with their own reports of perceived marital instability $(\beta=.06, p<.05)$ and husbands' reports of time spent using social networking websites were associated with their own reports of perceived marital instability $(\beta=.07, p<.05)$. Further, the partner effect of husbands' time using social networking websites being positively associated with wives' perceived marital instability $(\beta=.08, p<.01)$ also emerged. Two additional partner effects emerged, as well. Wives' reports of time spent watching television $(\beta=.08$, $p<.05)$ and gaming $(\beta=.07, p<.05)$ were both positively associated with husbands' reports of perceived marital instability.

\section{Reversed Directionality}

We estimated models with the directionality of the paths reversed because we recognized that marital quality might actually influence media usage rather than the other way around. The results of these models are shown in Table 3. None of the marital quality variables-satisfaction, conflict, and perceived marital instabilityshowed any association with television use. Husbands' perceived marital instability was positively associated with both wives' and husbands' reports of their own gaming ( $\beta=.10, p<.01$ in both models). Husbands' perceived marital instability was also positively associated with wives' $(\beta=.09, p<.05)$ and husbands' ( $\beta=.08, p<.05)$ reports of using social networking websites. Finally, wives' reports of marital conflict were associated with husbands' reports of using social networking websites $(\beta=.09, p<.05)$. The model fit was good for all three models.

Table 4 summarizes the significant findings from Tables 2 and 3. Of the twelve significant coefficients, five were actor effects and seven were partner effects. A roughly equal split of actor and partner effects validates our choice of using the APIM model. Had we not used the APIM model, these partner effects might not have been identified. Table 4 also shows that seven of the findings arose when media use was treated as the exogenous variable and marital quality the endogenous variable. We obtained two unique findings when marital quality was treated as the exogenous variable. Finally, three results emerged under both conditions.

\section{Media Use Differences}

Table 5 shows the results from the models using media use differences as predictors of marital satisfaction. The wife-husband difference in social networking was negatively associated with wives' reports of conflict ( $\beta=$ $-.09, p<.001)$. Because we subtracted husbands' scores from wives' scores, this suggests that as wives engage in social networking more than their husbands, wives' 
Table 4 Summary of relationships

\begin{tabular}{|c|c|c|}
\hline $\begin{array}{l}\text { Media use as } \\
\text { independent variable }\end{array}$ & $\begin{array}{l}\text { Marital quality as } \\
\text { independent variable }\end{array}$ & $\begin{array}{l}\text { Relationship found } \\
\text { in both } \\
\text { specifications }\end{array}$ \\
\hline $\begin{array}{l}\mathrm{W} \mathrm{TV} \rightarrow \mathrm{H} \text { perceived } \\
\text { marital instability } \\
(\beta=.08, p<.05)\end{array}$ & $\begin{array}{l}\mathrm{H} \text { perceived marital } \\
\text { instability } \rightarrow \mathrm{H} \\
\text { gaming }(\beta=.10, \\
p<.05)\end{array}$ & $\begin{array}{l}\text { W gaming \& } \mathrm{H} \\
\text { perceived marital } \\
\text { instability }\end{array}$ \\
\hline $\begin{array}{l}\mathrm{W} \text { gaming } \rightarrow \mathrm{W} \\
\text { conflict } \\
(\beta=.07, p<.05)\end{array}$ & $\begin{array}{l}\mathrm{H} \text { perceived marital } \\
\text { instability } \rightarrow \mathrm{W} \\
\text { social network } \\
\text { websites }(\beta=.09 \text {, } \\
p<.05)\end{array}$ & $\begin{array}{l}\text { H social network } \\
\text { websites \& W } \\
\text { conflict }\end{array}$ \\
\hline $\begin{array}{l}\text { W gaming } \rightarrow \text { Wives' } \\
\text { perceived marital } \\
\text { instability }(\beta=.06, \\
p<.05)\end{array}$ & & $\begin{array}{l}\mathrm{H} \text { social network } \\
\text { websites \& H } \\
\text { perceived marital } \\
\text { instability }\end{array}$ \\
\hline $\begin{array}{l}\mathrm{H} \text { TV } \rightarrow \text { Wives' } \\
\text { satisfaction } \\
\quad(\beta=-.08, p<.05)\end{array}$ & & \\
\hline $\begin{array}{l}\mathrm{H} \text { social network } \\
\text { websites } \rightarrow \mathrm{W} \\
\text { satisfaction } \\
(\beta=-.06, p<.05)\end{array}$ & & \\
\hline $\begin{array}{l}\text { H social network } \\
\text { websites } \rightarrow \mathrm{H} \\
\text { conflict }(\beta=.06, \\
p<.05)\end{array}$ & & \\
\hline $\begin{array}{l}\text { H social network } \\
\text { websites } \rightarrow \mathrm{W} \\
\text { perceived marital } \\
\text { instability }(\beta=.08 \text {, } \\
p<.05)\end{array}$ & & \\
\hline
\end{tabular}

Shaded cells indicate partner effects

reports of conflict were lower. Conversely, as husbands engage in social networking more than their wives, wives' reports of conflict were higher.

Table 5 also shows that the gaming difference squared variable was associated with the marital quality variables. The gaming difference squared term was negatively associated with both wives' $(\beta=-.06, p<.05)$ and husbands' $(\beta=-.08, p<.05)$ reports of marital satisfaction. Further, it was positively associated with husbands' reports of conflict $(\beta=.08, p<.01)$, and both wives' $(\beta=.06, p<.05)$ and husbands' $(\beta=.10$, $p<.05)$ reports of perceived marital instability. Interestingly, the linear difference term for gaming was never significant. This suggests a curvilinear association between gaming and marital quality was observed, such that any disparity in gaming, irrespective of whether it was the wife or the husband gaming more than their spouse, was associated with lower satisfaction and higher conflict and perceived marital instability. For the sake of illustration, we graphed predicted values of husbands' perceived marital instability at different values of gaming differences (Fig. 2).

\section{Discussion}

This exploratory study examined the association between entertainment media use and marital satisfaction, conflict, and perceived marital instability in a contemporary, national sample that had responses from both husbands and wives. We used both the actor partner interdependence model (APIM) and media difference scores to test the associations. In the APIM model, a number of actor and partner effects emerged. These associations all showed a negative relationship between the frequency of media use and marital quality. For example, wives' reports of gaming were positively associated with their own reports of conflict and perceived marital instability, whereas husbands' social networking website use was positively associated with their own reports of conflict, negatively associated with wives' satisfaction, and positively associated with wives' reports of perceived marital instability. These findings suggest that wives' gaming and husbands' social networking use may be problematic for married couples.

We also tested the models in reverse. A few findings did emerge. First, husbands' perceived marital instability was positively associated with their reports of gaming. Second, husbands' perceived marital instability was positively associated with wives' use of social networking websites.

In addition to testing the relationship between media use and marital quality using the APIM, we also examined whether differences in media use reports would be associated with relationship quality. As noted above, social networking website differences were positively associated with wives' marital quality. This finding fits nicely with the APIM model because of the way we coded the differences scores. Positive differences scores in social networking websites indicate that wives used them more. Thus, the more that wives used these websites relative to husbands, the happier they were in their relationship. Again this suggests that it may be problematic for husbands to engage in social network website use when it comes to marital quality.

The squared term for gaming also had many associations with the marital quality variables. The squared term for gaming was negatively associated with husbands' and wives' marital satisfaction. It was positively associated with husbands' reports of conflict and positively associated with both wives' and husbands' reports of perceived marital instability. Because the linear term for gaming differences was not significant, it did not matter whether the wife was gaming more or the husband was gaming more. Either 
Table 5 Differences in reported media use predicting marital satisfaction, conflict, and divorce proneness

\begin{tabular}{|c|c|c|c|c|c|c|c|c|c|c|c|c|}
\hline & \multicolumn{4}{|c|}{ Satisfaction } & \multicolumn{4}{|l|}{ Conflict } & \multicolumn{4}{|c|}{ Perceived marital instability } \\
\hline & \multicolumn{2}{|l|}{ Wives } & \multicolumn{2}{|c|}{ Husbands } & \multicolumn{2}{|l|}{ Wives } & \multicolumn{2}{|c|}{ Husbands } & \multicolumn{2}{|l|}{ Wives } & \multicolumn{2}{|l|}{ Husbands } \\
\hline & $\beta$ & $S E$ & $\beta$ & $S E$ & $\beta$ & $S E$ & $\beta$ & $S E$ & $\beta$ & $S E$ & $\beta$ & $S E$ \\
\hline Wife-husband television difference & .03 & .01 & -.01 & .01 & .01 & .01 & .01 & .01 & -.03 & .03 & .01 & .03 \\
\hline Wife-husband gaming difference & -.03 & .01 & -.01 & .01 & .05 & .01 & .02 & .01 & .05 & .03 & .02 & .03 \\
\hline $\begin{array}{l}\text { Wife-husband social networking website } \\
\text { difference }\end{array}$ & .05 & .01 & .05 & .01 & $-.09 * * *$ & .01 & -.05 & .01 & -.04 & .03 & -.02 & .03 \\
\hline Television difference squared & -.01 & .01 & -.01 & .01 & .05 & .01 & .01 & .01 & .03 & .01 & -.02 & .01 \\
\hline Gaming difference squared & $-.06^{*}$ & .01 & $-.08^{*}$ & .01 & .05 & .01 & $.08 * *$ & .01 & $.06^{*}$ & .01 & $.10 * * *$ & .01 \\
\hline Social networking website difference squared & -.06 & .01 & -.05 & .01 & .02 & .01 & .02 & .01 & .03 & .01 & .01 & .01 \\
\hline Participant age & -.04 & .01 & $-.07 * *$ & .01 & -.03 & .01 & -.02 & .01 & .05 & .01 & .05 & .01 \\
\hline Participant education & .04 & .01 & .01 & .01 & $-.06^{*}$ & .01 & -.05 & .01 & -.03 & .03 & -.04 & .02 \\
\hline Total household income & .01 & .01 & .03 & .01 & -.05 & .01 & -.05 & .01 & $-.08 * *$ & .02 & $-.06^{*}$ & .02 \\
\hline $\mathrm{R}^{2}$ & .01 & & .01 & & .03 & & .02 & & .02 & & .02 & \\
\hline \multicolumn{13}{|l|}{ Path model fit statistics: } \\
\hline$X^{2}$ & \multicolumn{4}{|c|}{$136.24 * * *$} & \multicolumn{4}{|l|}{$116.61 * * *$} & \multicolumn{4}{|c|}{$131.13 * * *$} \\
\hline CFI & \multicolumn{4}{|l|}{.97} & \multicolumn{4}{|l|}{.98} & \multicolumn{4}{|l|}{.97} \\
\hline RMSEA & \multicolumn{4}{|l|}{.06} & \multicolumn{4}{|l|}{.05} & \multicolumn{4}{|l|}{.05} \\
\hline
\end{tabular}

Satisfaction, conflict, and perceived marital instability were analyzed in separate path models

$* p<.05 . * * p<.01$. *** $p<.001$

Fig. 2 Husbands' predicted perceived marital instability scores by gaming difference between wife and husband

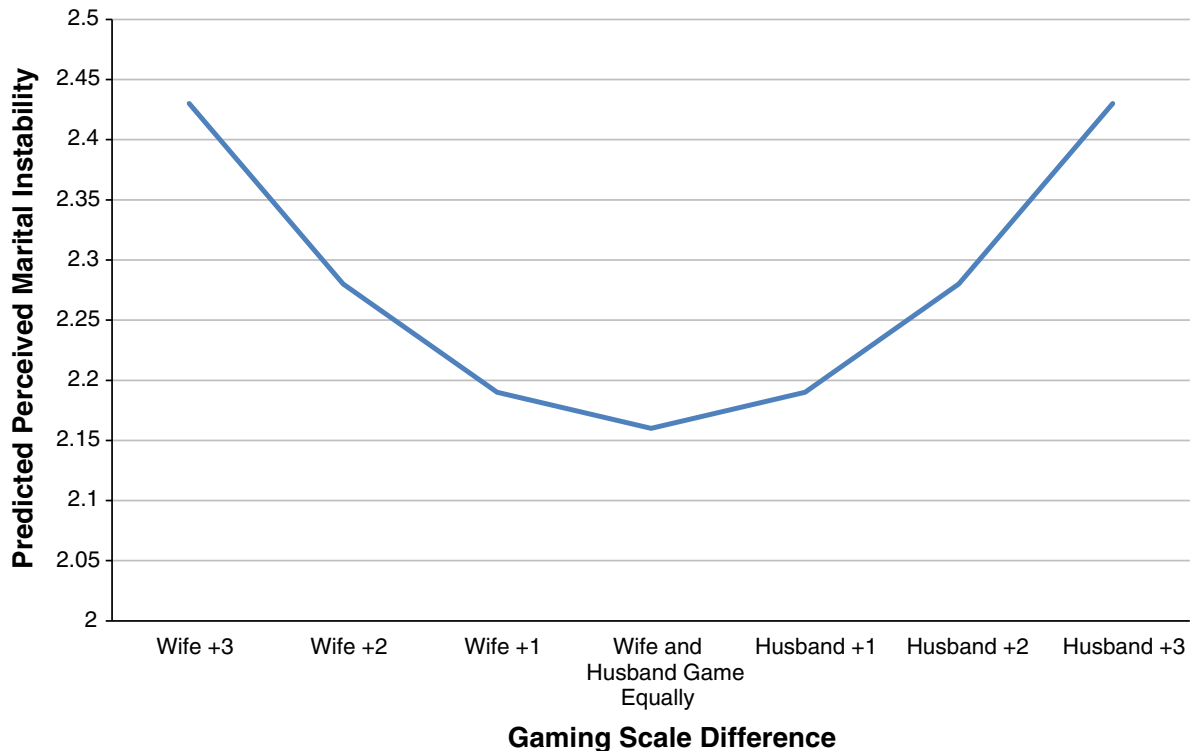

Gaming Scale Difference scenario would be predicted to be associated with lower levels of marital quality.

These findings largely support our initial hypotheses. That is, based on previous research we thought that gaming and social network website use would be negatively associated with marital satisfaction and positively associated with conflict and perceived marital instability. For the most part, these newer types of media use were indeed negatively associated with participants' and spouses' marital quality. Further, the negative association between husbands' use of social networking websites and husbands' and wives' marital quality emerged in both the APIM and the difference-score models.

Explaining the Findings through the Nature of Entertainment Media

In keeping with the exploratory nature of our study, we offer some tentative explanations of the findings. Nearly all of the negative results involved newer technology such as 
social networking websites and video games rather than older technology like television. Both of these forms of entertainment media have an interactive element; television requires consumption only. This may suggest that media with more interactive components may intrude into marriage relationships more than other types (see also Lanigan 2009). As individual spouses interact more with these types of media, it may detract from their marriage. Alternatively, video gaming and social networking websites offer connections and interactions with individuals outside of the marriage relationship. These relationships may also detract from the marriage. Given that the effect sizes were small, however, this may suggest these problems only arise for a minority of couples.

Gendered social norms may combine with the type of media used to create some of these associations. For example, five of the twelve significant coefficients in the APIM models related to husbands' use of social networking websites. There are two potential explanations for this finding. The first involves the partner effects that the amount of husbands' social networking use was negatively associated with wives' marital quality variables. The nature of social networking and social gender norms about online communication may lead husbands' greater use of social networking to be associated with poorer marital quality. Researchers have proposed that women are more likely to engage in communication to build relationships regardless of the medium, and so women, in general, are more likely to use online forums to build relationships than are men (Baym et al. 2007). We certainly found support for this behavior in the data. We found that only $21 \%$ of the wives reported never spending time on social networking websites, whereas $40 \%$ of husbands reported never spending time on social networking websites. Using a matched $t$ test we found that the mean difference between the amount of time that wives and husbands spend on social networking websites was statistically significant $(t=14.06, p<.001)$. Further, Coyne et al. (2011) also found that women in their study were more likely to make connections with others through media than were men. Thus, wives may have a marital expectation (based on social gender norms) that their husbands will not use social networking websites much. When husbands violate that expectation, wives may report less marital quality.

Although the gendered social norms about online behavior may explain the partner effect, it does not readily account for the actor effect of husbands' social networking being positively associated with husbands' perceived marital instability. A second explanation for this finding could be that the direction of this relationship may be the reverse of what we specified. It may be the case that husbands who perceived their relationship to be unstable were using social networking for longer periods of time to compensate or cope with the instability. They may have been seeking to strengthen positive relationships with friends online or to develop new positive relationships (including romantic relationships) with other individuals. We tested the association in both directions, and the actor effect was significant in both models. We would need longitudinal data to further investigate this finding, however.

Another noteworthy finding that relates to the type of media use was that the squared term for video gaming accounted for five of the six significant media findings in the difference score models. Gaming may be associated, for some, with addiction and lowered social interactions. Indeed, researchers have found that video gaming is associated with interference with personal responsibilities (Dauphin and Heller 2010), and that online video gaming sometimes replaces offline social relationships (Sublette and Mullan 2010). Both addiction and lower interaction have potential to be costs in a marriage relationship, thus providing a rationale for gaming having an impact on marital quality. The findings, though, specify that one spouse has to engage in this behavior more than the other before gaming relates to marital quality. Thus, gaming per se is not necessarily a problem-spouses had the highest quality when they had the same levels of gaming whether it was high or low. This suggests that spouses who both game may be able to use it as a relationship building tool, whereas if one spouse has no interest in gaming, the other spouses' gaming may be problematic for the marriage.

Lanigan (2009) noted that there is a bidirectional relationship between the technology being studied and both family and individual factors. Although in the present study it is not possible to determine time order between technology and marital satisfaction, the fact that there is potential for a bidirectional relationship between the marital relationship, individuals in the marriage, and the technology used is clear.

\section{Small Associations}

In making these suppositions, we must note that the effect sizes of the relationship between media use were small. The standardized coefficients ranged from .06 to .13 in magnitude. Thus, we do not want to overstate the association between entertainment media use and marital quality. Although effect sizes are often small when examining marital quality in national samples, these small effect sizes deserve discussion.

It may be that our media use questions measured media use less reliably. For example, time-diary data might have more reliably shown the actual amount of time that participants' spent using each type of entertainment media (Robinson and Godbey 1999). Further, it may be that 
because our measures confound joint media use, which is likely beneficial to relationship quality, and individual media use, which may not be beneficial, this might have limited the reliability of our measures. Low reliability would then contribute to lower associations between media use and marital quality than actually exist in reality.

Alternatively, it may be that the association between media use and marital quality is, in reality, relatively small. Other activities and/or relationship processes simply might be more strongly related to wives' and husbands' relationship quality. Media use may fit into the context of other family activities and it is the entire context of couples' time use that matters more than any one individual activity.

An alternative explanation that fits the findings is that entertainment media use may only be a major problem for a minority of couples. These effects would then be washed out when aggregated with other couples for whom media use is not an issue. In spite of these small associations, we detail the value of this study in the implication and conclusion section.

\section{Limitations}

This study has limitations that future studies of media use might overcome. First, the data were cross-sectional. Thus, we were not able to make statements about the directions of some of the effects. For example, men who perceive that they are in unstable marriages might cope by using social networking as a way to build other relationships, whereas men in more stable marriages might not face this pressure.

Another limitation was the use of self-report data. Some participants may have desired to appear happier in their relationships and so reported higher levels of marital quality (e.g., greater satisfaction, less conflict). This socialdesirability issue would only cause problems for the findings themselves if the bias were systematically related to media use. This is unlikely, but the fact that we used selfreport data is still a limitation of our study.

\section{Implications and Conclusion}

As couples navigate newer entertainment media, they may need to be mindful of potential impacts of media use on their marriage. Because both marital instability and conflict are positively associated with entertainment media use, individuals should consider the meaning of involvement in entertainment media personally as well as relationally.

Our study also offers additional methodological suggestions for researchers studying media use and family relationships. First, our study suggests that it is important to get both participants' and spouses'/partners' reports of media use and marital quality. We found interesting actor and partner effects as well as gendered findings. Second, our study shows the importance of considering that the association may work both ways. Third, future research on the association between media use and marital quality might also profitably use longitudinal data to answer questions about the direction of the associations. Future research examining media use within couples would also do well to differentiate between joint and individual media use.

Finally, these findings suggest that media use might be one of those phenomena in family life that take up time, energy, and attention and that deserve great scholarly attention (Daly 2003). It also suggests that contemporary entertainment media use may pose a new set of problems for married couples.

Acknowledgments The authors would like to acknowledge a grant from the Science of Generosity Initiative at the University of Notre Dame that enabled us to collect the data used in this study. All statements in this study are the authors'.

\section{References}

Ahlstrom, M., Lundberg, N. R., Zabriskie, R., Eggett, D., \& Lindsay, G. B. (2012). Me, my spouse, and my avatar: The relationship between marital satisfaction and playing massively multiplayer online role-playing games (MMPORG's). Journal of Leisure Research, 44, 1-22.

Baym, N. K., Zhang, Y. B., Kunkel, A., Ledbetter, A., \& Lin, M. C. (2007). Relational quality and media use in interpersonal relationships. New Media and Society, 9, 735-752. doi:10. 1177/1461444807080339.

Bryant, J., \& Zillmann, D. (1984). Using television to alleviate boredom and stress: Selective exposure as a function of induced excitational states. Journal of Broadcasting, 28, 1-20. doi:10. $1080 / 08838158409386511$.

Bureau of Labor Statistics (2010). American time use survey summary. Retrieved from http://www.bls.gov/news.release/atus.nr0.htm.

Chesley, N. (2005). Blurring boundaries? Linking technology use, spillover, individual distress, and family satisfaction. Journal of Marriage and Family, 67, 1237-1248. doi:10.1111/j.1741-3737. 2005.00213.x.

Clayton, R. B., Nagurney, A., \& Smith, J. R. (2013). Cheating, breakup, and divorce: Is Facebook use to blame? Cyberpsychology, Behavior, and Social Networking, 16, 717-720. doi:10. 1089/cyber.2012.0424.

Cole, H., \& Griffiths, M. D. (2007). Social interactions in massively multiplayer online role-playing gamers. CyberPsychology and Behavior, 10, 575-583. doi:10.1089/cpb.2007.9988.

Correa, T., Hinsley, A. W., \& de Zúñiga, H. G. (2009). Who interacts on the Web? The intersection of users' personality and social media use. Computers in Human Behavior, 26, 247-253. doi:10. 1016/j.chb.2009.09.003.

Coyne, S. M., Busby, D., Bushman, B. J., Gentile, D. A., Ridge, R., \& Stockdale, L. (2012). Gaming in the game of love: Effects of video games on conflict in couples. Family Relations, 61, 388-396. doi:10.1111/j.1741-3729.2012.00712.x.

Coyne, S. M., Stockdale, L., Busby, D., Iverson, B., \& Grant, D. M. (2011). "I luv u \#xF04A;!": A descriptive study of the media use of individuals in romantic relationships. Family Relations, 60 , 150-162. doi:10.1111/j.1741-3729.2010.00639.x. 
Daly, K. (2003). Family theory versus the theories families live by. Journal of Marriage and Family, 65, 771-784. doi:10.1111/j. 1741-3737.2003.00771.x.

Dauphin, B., \& Heller, G. (2010). Going to other worlds: The relationships between videogaming, psychological absorption, and daydreaming styles. Cyberpsychology, Behavior, and Social Networking, 13, 169-172. doi:10.1089/cyber.2009.0065.

Dew, J. P. (2007). Do you have the time? Changes in and implications of spouses' time together (Doctoral dissertation). Retrieved from UMI (Order Number 3266098).

Doran, K. \& Price, J. (2014). Pornography and marriage. Journal of Family and Economic Issues. Advance online publication. doi: 10.1007/s10834-014-9391-6

Fincham, F. D., \& Beach, S. R. H. (2010). Marriage in the new millennium: A decade in review. Journal of Marriage and Family, 72, 630-649. doi:10.1111/j.1741-3737.2010.00722.x.

Gantz, W. (1985). Exploring the role of television in married life. Journal of Broadcasting and Electronic Media, 29, 65-78.

Glorieux, I., Minnen, J., \& van Tienoven, T. P. (2011). Spouse "together time": Quality time within the household. Social Indicators Research, 101, 281-287. doi:10.1007/s11205-0109648-x.

Hand, M. M., Thomas, D., Buboltz, W., Deemer, E., \& Buyanjargal, M. (2013). Facebook and romantic relationships: Intimacy and couple satisfaction associated with online social network use. CyberPsychology, Behavior, and Social Networking, 16, 8-16. doi:10.1089/cyber.2012.0038.

Henning, B., \& Vorderer, P. (2001). Psychological escapism: Predicting the amount of television viewing by need for cognition. Journal of Communication, 51, 100-120. doi:10. 1111/j.1460-2466.2001.tb02874.x.

Hertlein, K. M., \& Hawkins, B. P. (2012). Online gaming issues in offline couple relationships: A primer for marriage and family therapists (MFTs). The Qualitative Report, 17(15), 1-48.

Hill, M. S. (1988). Marital stability and spouses' shared time: A multidisciplinary hypothesis. Journal of Family Issues, 9, $427-451$.

Hughes, R., \& Hans, J. D. (2001). Computers, the internet, and families: A review of the role new technology plays in family life. Journal of Family Issues, 22, 776-790. doi:10.1177/ 019251301022006006.

Kashy, D. A., \& Kenny, D. A. (2000). The analysis of data from dyads and groups. In H. T. Reis \& C. M. Judd (Eds.), Handbook of research methods in social psychology (pp. 451-477). New York: Cambridge University Press.

Kendall, T. D. (2011). The relationship between internet access and divorce rate. Journal of Family and Economic Issues, 32, 449-460. doi:10.1007/s10834-010-9222-3.

Kenny, D. A., Kashy, D. A., \& Cook, W. L. (2006). Dyadic Data Analysis. New York: Guilford Press.

Lanigan, J. D. (2009). A sociotechnological model for family research and intervention: How information and communication technologies affect family life. Marriage and Family Review, 45, 587-609. doi:10.1080/01494920903224194.

Muise, A., Christofides, E., \& Desmarais, S. (2009). More information than you ever wanted: Does Facebook bring out the greeneyed monster of jealousy? CyberPsychology and Behavior, 12, 441-444. doi:10.1089/cpb.2008.0263.

Networks, Knowledge. (2011). Knowledge Networks Project Report: Marital Generosity Survey. Menlo Park, CA: Knowledge Networks.

Osborn, J. L. (2012). When TV and marriage meet: A social exchange analysis of the impact of television viewing on marital satisfaction and commitment. Mass Communication and Society, 15, 739-757. doi:10.1080/15205436.2011.618900.

Padilla-Walker, L. M., Nelson, L. J., Carroll, J. S., \& Jensen, A. C. (2010). More than just a game: Video game and Internet use during emerging adulthood. Journal of Youth and Adolescence, 39, 103-113. doi:10.1007/s10964-008-9390-8.

Reinecke, L. (2009). Games and recovery: The use of video and computer games to recuperate from stress and strain. Journal of Media Psychology, 21, 126-142. doi:10.1027/1864-1105.21.3. 126.

Robinson, J. P., \& Godbey, G. (1999). Time for Life. University Park, PA: Pennsylvania State University.

Sublette, V. A., \& Mullan, B. (2010). Consequences of play: A systematic review of the effects of online gaming. International Journal of Mental Health and Addiction, Online First. doi: 10. 1007/s11469-010-9304-3

Walker, K., Krehbiel, M., \& Knoyer, L. (2009). "Hey you! Just stopping by to say hi!": Communicating with friends and family on MySpace. Marriage and Family Review, 45, 677-696. doi:10. 1080/01494920903224251.

Yadama, G. N., \& Pandey, S. (1995). Effect of sample size on goodness-of-fit indices in structural equation models. Journal of Social Service Research, 20, 49-70.

Jeffrey Dew is an Associate Professor in the Department of Family, Consumer, and Human Development at Utah State University. He teaches family studies courses and graduate level statistics courses. He researches the association between family resources (money and time) and family relationships. Dew received a dual-title $\mathrm{PhD}$ in Demography and Human Development and Family Studies from the Pennsylvania State University.

Sarah Tulane is a Clinical Assistant Professor of Family, Consumer, and Human Development at Utah State University. Dr. Tulane's research interests include adolescent psychosocial development, technology and relationships, and family life education. Dr. Tulane received her $\mathrm{PhD}$ from Utah State University. 